\title{
Proceeding
}

Supplementary Issue: Spring Conferences of Sports Science. Costa Blanca Sports Science Week, 26-28 April 2018. Calpe.

Alicante, Spain

\section{Correlation of the anthropometric characteristics and the ability to jump in volleyball}

\author{
TIZIANA D'ISANTO1 ${ }^{4}$, PIO ALFREDO DI TORE1, GAETANO ALTAVILLA2 \\ ${ }^{1}$ MIUR Campania, Italy \\ ${ }^{2}$ Faculty of Kinesiology, University of Split, Split, Croatia
}

\begin{abstract}
Volleyball is a sport of situation classified among the activities with an alternate aerobic - anaerobic commitment, which requires a high use of large muscular masses, with an accentuated prevalence of the anaerobic alactacid metabolism. The purpose of this work is to analyze and evaluate the correlations between the various variables of an anthropometric and functional nature, studied by testing a population of high-level volleyball players (Under 20 elite), subdividing them according to the role it occupied inside the group. The study was carried out on 42 volleyball players divided into four groups. In all subjects the following anthropometric parameters were assessed: height, weight, body mass index (BMI), height with a stretched arm (AH1) and height with two extended arms (AH2). The indirect measurement of the explosive force was carried out with the Bosco method: squat jump (SJ), counter movement jump (CMJ), CMJ with the use of the arms (CMJas). The elevation and coordination skills were assessed with the Vertec test using the technical gesture of the attack (Vertec attack, VA) and the wall (Vertec wall, VW). Other data can be obtained by evaluating the results obtained by the difference between the measurement of the Vertec attack (VA) and the height with a stretched arm (AH1) and between that of the Vertec wall (VW) and the height with two outstretched arms (AH2). The results of the anthropometric parameters showed significant differences in height $(F=4.7 ; p<0.006)$, height with a stretched arm AH1 $(F=3.5 ; p<0.02)$ and height with two outstretched arms $\mathrm{AH} 2(\mathrm{~F}=3.5 ; p<0.02)$. In the comparison by role we did not obtain any statistical significance regarding the Bosco test. A high correlation was found between the results of the anthropometric parameters and those of the Vertec. The results show that in high-level youth volleyball, the athletes' anthropometric profile is directly linked to variables that must be used for the selection of talents and for training planning. Key words: PLAYERS AND ROLES, BOSCO TEST, VERTEC TEST, TRAINING -TALENT SCOUTING.
\end{abstract}

\section{Cite this article as:}

D'Isanto, T., Di Tore, P. \& Altavilla, G. (2018). Correlation of the anthropometric characteristics and the ability to jump in volleyball. Journal of Human Sport and Exercise, 13(2proc), S393-S400. doi:https://doi.org/10.14198/jhse.2018.13.Proc2.23

Corresponding author. MIUR Campania, Italy. http://orcid.org/0000-0001-7151-7486

E-mail: tizidisanto@libero.it

Supplementary Issue: Spring Conferences of Sports Science. Costa Blanca Sports Science Week, 26-28 April 2018. Calpe. Alicante, Spain.

JOURNAL OF HUMAN SPORT \& EXERCISE ISSN 1988-5202

(c) Faculty of Education. University of Alicante

doi: 10.14198/jhse.2018.13.Proc2.23 


\section{INTRODUCTION}

Volleyball is a sport with technical and physical characteristics where the precision e la power is the most important aspect for achieve a winning action (D'Isanto et al, 2017) and it is a game sport that includes some aspects of human science and experimental science to analyze descriptively the movement (Parisi \& Raiola, 2014b, Raiola, 2012, Raiola \& Di Tore, 2012abc). It within the physiological classification of sporting activities is defined as an alternate aerobic-anaerobic activity with the use of a high percentage of the body's muscular masses and high-level force demands (Polgaze, \& Dawson, 1992). The characteristics of the game include passive phases that have a duration of about 15 seconds, while the active phases have two intervals, the first lasts less than 3 seconds (errors on the stop and points made directly from the serve) and the second lasts about 5 seconds. The first interval is explained by the prevalence of the jump in serve and the high number of errors and points made directly. The second interval, which develops within 5 seconds, is linked to the high number of actions ending with 4-5 touches. This type of commitment in volleyball increases the anaerobic alactacid commitment (Gaetano \& Rago, 2014), so the training of aerobic capacity is not specific and contraindicated (Katch, \& Weltman, 1979). In modern volleyball the use of the jump and the speed of play is a clear sign of a greater demand for physical strength and the speed of the technical gesture (Raiola et al, 2016). In fact, in the selection of young talents the explosive dynamic strength, the elevation and the speed of displacement are selective and determining (Ashley, \& Weiss, 1994); while physical demands during a training or the match differ from each playing position (Rago et al, 2017; Altavilla et al, 2017). The analysis of the workload during the competition is fundamental for training planning (Altavilla, \& Raiola, 2018; Raiola, 2014; Raiola et al, 2013; Gaetano, 2012), since physical training is increasingly characterized by the integration of exercises that reproduce specific technical-tactical gestures (Bosco et al, 1994). However, performance is also linked to other qualities such as neuro-muscular coordination, motor control (Raiola, 2017; Raiola \& Di Tore, 2017), tactical attitudes and motivational characteristics (Fontani et al, 1998). A tool that can analyze and make analysis easier is undoubtedly the video analysis, that enables revision and a focus on the strengths and weaknesses of the team, both in tactics and technique (Parisi \& Raiola, 2014a). The evaluate teaching method is the specific goal of the teachers of physical education and the coaches of sports (Cirillo et al, 2016). The aim of this study is to analyze and evaluate the correlations between the various variables of an anthropometric and functional nature, studied by testing a population of volleyball players (under 20 of Italian elite), subdividing them according to their role; for verify if the players anthropometric profile is directly linked to some variables that must be used for the selection of talents and for training planning.

\section{MATERIALS AND METHODS}

\section{Sample of subjects}

The survey was performed on a sample of 42 male volleyball players who have been practicing this discipline for at least 5 years of competitive activity and participate on average 5 weekly training sessions. The tests were carried out on a group of athletes participating in the under-20 Italian elite championship. The volleyball players were divided into four categories according to their role: side spikers, n.14; age: $18.7 \pm 1.5$ years, central spikers, n.15; age: $18.3 \pm 1.3$ years, setters, n.7; age: $18.5 \pm 1.4$ years, and universal spikers, n.6; age: $17.6 \pm 0.9$ years. The age of the players did not differ significantly from one group to another $(F=1.15$; $p=0.35$.

\section{Details on experimental procedure}

The Ergojump Bosco System consists in the indirect evaluation of the dynamic-explosive force, of the explosive force and of the alactacid anaerobic power through calculation of the vertical displacement of the 
center of gravity with the Bosco method (Bosco et al, 1983). With this test we measure the height reached by performing jumps with different techniques. Each test is characterized by the execution of three jumps: for the statistical survey the best result is considered. The execution of the jumps is done using a conductivity platform connected to a microprocessor. The athletes perform a series of jumps that provide data subsequently processed by a software program that calculates the contact and flight times in milliseconds, the heights in centimeters and the powers in watts. In this study 3 tests of the test battery developed by Bosco were used: Squat Jump (SJ), Counter Movement Jump (CMJ), Counter Movement Jump with the use of the arms (CMJ as). Was considered, then, the difference in $\mathrm{cm}$ obtained from the results of the CMJ and the SJ (CMJ-SJ). This value gives indications on the ability of the subject to use elastic energy (Bobbert et al, 1996; Komi, \& Bosco, 1978). The Squat-Jump (SJ) allows to evaluate the explosive strength of the lower limbs. From the difference of the results of the first two tests (CMJ-SJ) a value is obtained that represents an index to evaluate the elasticity of the extensor muscles of the lower limbs. The Counter Movement Jump (CMJ as) with the use of the arms is characterized by a jump with counter-movement, with the use of the upper limbs. While, the Vertec test was used to measure and evaluate the elevation in a specific way (Isaacs, 1998), using the technical action of the attack to net (VA) and the wall action (VW). Each player simulates the attack action with a run-up step (VA) and the wall action (VW). For each test three tests are carried out: of the jumps performed only the best result will be considered for the statistical analysis. Other data can be obtained by evaluating the results obtained by the difference between the measurement of the attack action with a runup step (VA) and the maximum measure reached by extending the dominant arm (AH1), between the technical action of the wall from a standstill (VM) and the maximum measure reached by completely extending the upper limbs (AH2). In this way it is possible to calculate the elevations obtained by the various players by jumping with and without run-up. The result in $\mathrm{cm}$ of elevation using the run-up, (difference with run-up, DRU), is obtained from the difference between VA and $\mathrm{AH} 1$ while the one without run-up (difference without run-up, DWRU) corresponds to the difference between VW and AH2. Other data that we have obtained concern the difference between the two evaluated elevation forms (DRU-DWRU = DIF in $\mathrm{cm}$ ).

\section{Statistics analysis}

Data on anthropometric characteristics and results from the Bosco and the Vertec test are presented as mean and standard deviation (SD). For the comparison of the anthropometric data and of the jumping capacities according to the playing position, one-factor variance analysis was performed. The correlations between all the variables considered were calculated using the Pearson correlation coefficient. Statistical analysis was performed using SPSS 22.0 (SPSS Inc., Chicago, IL, USA). For all the performed analyses, a p-value $<0.05$ was considered significant.

\section{RESULTS}

Tables 1 and 2 show the mean and the standard deviation of the anthropometric values and of the jump capacities of all the volleyball players considered. The results of the comparison of the anthropometric parameters and of the jumping capacities according to the role, are instead shown in Tables 3 and 4. Regarding the anthropometric data, we obtained significant results for the height $(F=4.7 ; p<0.006), A H 1$ measured with a stretched $\operatorname{arm}(F=3.5 ; p<0.02)$ and $\mathrm{AH} 2$ measured with two outstretched arms $(F=3.5 ; p$ $<0.02)$. The group of central spikers $(C)$ reached higher values of the setters $(S)$ : height $(C: 198.4 \pm 4.2 \mathrm{~cm}$ vs P: $190.8 \pm 3.5 \mathrm{~cm}, \mathrm{p}<0.01$ ), AH1 (C: $261.6 \pm 7.1 \mathrm{~cm}$ vs S: $251.7 \pm 5.4 \mathrm{~cm} ; \mathrm{p}<0.01$ and AH2 (C: $257.7 \pm$ $7.1 \mathrm{~cm}$ vs $\mathrm{S}: 248.2 \pm 4.5 \mathrm{~cm} ; \mathrm{p}<0.05)$. In the comparison by roles we did not get any statistical difference with regards to the Bosco test. The results of the Vertec test, instead, show significant variations with respect to the VA ( $F=7.3 ; p<0.001)$, with the central spikers having an elevation superior to the setters ( $\mathrm{C}: 335.7 \pm$ $6.2 \mathrm{~cm}$ vs $S 326.1 \pm 8.5 \mathrm{~cm} ; \mathrm{p}<0.01)$ and to the universal spikers $(U)(C: 335.7 \pm 6.2 \mathrm{~cm}$ vs $U 326.4 \pm 2.3$ 
$\mathrm{cm} ; \mathrm{p}<0.01)$ and the VW $(\mathrm{F}=3.94, p<0.05)$ and are always the central spikers that perform better performance in the jump that uses the wall technique than the setters (C: $314.6 \pm 7.7 \mathrm{~cm}$ vs S $302,8 \pm 8.2$ $\mathrm{cm} ; \mathrm{p}<0.01)$. The analysis of the correlation matrix shows that height and weight are correlated with each other and with $\mathrm{AH} 1$ and $\mathrm{AH} 2$ (table 5). As far as the tests of the Bosco and Vertec tests are concerned, the different variables of each test are correlated with each other and with DRU and DWRU. With the Bosco test, the information obtained concerns the ability to jump not connected to technical gestures; differently with the Vertec Test more specific indications were found on the neuro-motor coordination skills. A high correlation has been found between the results of the anthropometric parameters and those of the Vertec Test.

Table 1. Anthropometric values of all players

\begin{tabular}{cc}
\hline Variables & Average $\pm \mathbf{S D}(\boldsymbol{n}=\mathbf{4 2})$ \\
\hline Height $(\mathrm{cm})$ & $194,7 \pm 4,1$ \\
Weight $(\mathrm{kg})$ & $84,2 \pm 3,28$ \\
$\mathrm{BMI}\left(\mathrm{kg} / \mathrm{cm}^{2}\right)$ & $22,2 \pm 1,2$ \\
$\mathrm{AH} 1(\mathrm{~cm})$ & $256,7 \pm 6,8$ \\
$\mathrm{AH} 2(\mathrm{~cm})$ & $253,2 \pm 6,7$ \\
\hline
\end{tabular}

Table 2. Results of the jump capacity tests

\begin{tabular}{|c|c|}
\hline Variables & Average $\pm S D(n=42)$ \\
\hline \multicolumn{2}{|c|}{ Bosco Test } \\
\hline SJ (cm) & $37,3 \pm 3,2$ \\
\hline $\mathrm{CMJ}(\mathrm{cm})$ & $41,6 \pm 3,7$ \\
\hline CMJ-SJ (cm) & $4,35 \pm 1,6$ \\
\hline CMJas (cm) & $49,9 \pm 4,3$ \\
\hline \multicolumn{2}{|r|}{ Vertec test } \\
\hline $\mathrm{VA}(\mathrm{cm})$ & $329,8 \pm 7,4$ \\
\hline VW (cm) & $307,5 \pm 8,1$ \\
\hline \multicolumn{2}{|c|}{ Combined data } \\
\hline $\mathrm{DRU}(\mathrm{cm})$ & $73,1 \pm 5,4$ \\
\hline $\mathrm{DWRU}(\mathrm{cm})$ & $54,3 \pm 5,7$ \\
\hline DIF (cm) & $18,8 \pm 5,1$ \\
\hline
\end{tabular}


Table 3. Comparison of anthropometric parameters according to the role

\begin{tabular}{|c|c|c|c|c|c|c|}
\hline Variables & $\begin{array}{c}\text { Side spikers } \\
(\mathbf{n}=14)\end{array}$ & $\begin{array}{c}\text { Central spikers } \\
(\mathbf{n}=15)\end{array}$ & $\begin{array}{c}\text { Setters } \\
(\mathbf{n}=7)\end{array}$ & $\begin{array}{c}\text { Universal spikers } \\
(\mathbf{n}=6)\end{array}$ & $\mathbf{F}$ & $\mathbf{p}$ \\
\hline Height $(\mathrm{cm})$ & $195,4 \pm 4,2$ & $198,4 \pm 4,2$ & $190,8 \pm 3,6$ & $193,5 \pm 5,2$ & 4,7 & 0,006 \\
\hline Weight $(\mathrm{kg})$ & $85,9 \pm 6,2$ & $88,5 \pm 4,8$ & $80,5 \pm 5,4$ & $82,2 \pm 8,1$ & 1,5 & 0,22 \\
\hline $\begin{array}{c}\mathrm{BMl} \\
\left(\mathrm{kg} / \mathrm{cm}^{2}\right)\end{array}$ & $22,4 \pm 1,5$ & $22,4 \pm 1,4$ & $22,1 \pm 1,3$ & $21,9 \pm 1,5$ & 0,3 & 0,70 \\
\hline $\mathrm{AH} 1(\mathrm{~cm})$ & $257,1 \pm 6,6$ & $261,6 \pm 7,1$ & $251,7 \pm 5,4$ & $256,5 \pm 6,3$ & 3,5 & 0,02 \\
\hline $\mathrm{AH} 2(\mathrm{~cm})$ & $254,4 \pm 6,3$ & $257,7 \pm 7,1$ & $248,2 \pm 4,5$ & $252,5 \pm 6,4$ & 3,5 & 0,02 \\
\hline
\end{tabular}

Table 4. Comparison tests of jumping ability according to the role

\begin{tabular}{|l|c|c|c|c|c|c|}
\hline Variables & $\begin{array}{c}\text { Side spikers } \\
(\mathbf{n = 1 4})\end{array}$ & $\begin{array}{c}\text { Central spikers } \\
(\mathbf{n = 1 5})\end{array}$ & $\begin{array}{c}\text { Setters } \\
(\mathbf{n = 7})\end{array}$ & $\begin{array}{c}\text { Universal } \\
\text { spikers }(\mathbf{n = 6})\end{array}$ & $\mathbf{F}$ & $\mathbf{p}$ \\
\hline \multicolumn{7}{|c|}{ Bosco Test } \\
\hline SJ (cm) & $37,2 \pm 3,8$ & $39,1 \pm 2,5$ & $36,4 \pm 5,1$ & $36,5 \pm 4,6$ & 1,12 & 0,377 \\
\hline CMJ (cm) & $41,7 \pm 3,9$ & $43,3 \pm 1,9$ & $40,9 \pm 6,1$ & $40,7 \pm 4,8$ & 0,68 & 0,524 \\
\hline $\begin{array}{l}\text { CMJ-SJ } \\
(\mathrm{cm})\end{array}$ & $4,5 \pm 1,4$ & $4,2 \pm 1,5$ & $4,5 \pm 1,3$ & $4,2 \pm 1,3$ & 0,25 & 2,204 \\
\hline CMJas (cm) & $50,1 \pm 4,6$ & $51,7 \pm 2,9$ & $49,1 \pm 6,7$ & $48,8 \pm 7,5$ & 0,73 & 0,568 \\
\hline \multicolumn{7}{|c|}{ Vertec Test } \\
\hline VA (cm) & $331,2 \pm 6,6$ & $335,7 \pm 6,2$ & $326,1 \pm 8,5$ & $326,4 \pm 2,3$ & 7,30 & 0,001 \\
\hline VW $(\mathrm{cm})$ & $308,1 \pm 8,7$ & $314,6 \pm 7,7$ & $302,8 \pm 8,2$ & $304,5 \pm 5,1$ & 3,94 & 0,015 \\
\hline \multicolumn{7}{|c|}{ Combined data } \\
\hline DRU (cm) & $74,1 \pm 4,9$ & $75,8 \pm 6,2$ & $72,1 \pm 4,0$ & $70,5 \pm 6,0$ & 2,58 & 0,061 \\
\hline DWRU (cm) & $54,8 \pm 6,2$ & $55,9 \pm 6,8$ & $53,7 \pm 5,9$ & $52,8 \pm 2,7$ & 0,49 & 0,728 \\
\hline DIF $(\mathrm{cm})$ & $19,3 \pm 4,5$ & $19,9 \pm 5,1$ & $18,4 \pm 3,7$ & $17,7 \pm 6,2$ & 1,43 & 0,253 \\
\hline
\end{tabular}

Table 5. Correlation matrix (anthropometric variables and jumping ability)

\begin{tabular}{|c|c|c|c|c|c|c|c|c|c|c|c|}
\hline & Age & Height & Weight & AH1 & AH2 & SJ & CMJ & CMJ-SJ & CMJas & VA & VW \\
\hline Age & - & & & & & & & & & & \\
\hline Height & 0,018 & - & & & & & & & & & \\
\hline Weight & 0,170 & 0,629 & - & & & & & & & & \\
\hline AH1 & 0,130 & 0,860 & 0,690 & - & & & & & & & \\
\hline AB2 & 0,110 & 0,875 & 0,674 & 0,991 & - & & & & & & \\
\hline SJ & 0,075 & $-0,340$ & $-0,356$ & $-0,295$ & $-0,325$ & - & & & & & \\
\hline CMJ & 0,150 & $-0,295$ & $-0,282$ & $-0,195$ & $-0,235$ & 0,933 & - & & & & \\
\hline CMJ-SJ & 0,220 & 0,115 & 0,186 & 0,255 & 0,240 & $-0,131$ & 0,234 & - & & & \\
\hline CMJas & 0,155 & $-0,275$ & $-0,239$ & $-0,250$ & $-0,296$ & 0,737 & 0,813 & 0,246 & - & & \\
\hline VA & 0,182 & 0,595 & 0,392 & 0,705 & 0,680 & 0,198 & 0,264 & 0,190 & 0,215 & - & \\
\hline VW & 0,292 & 0,640 & 0,442 & 0,730 & 0,705 & 0,109 & 0,245 & 0,379 & 0,107 & 0,835 & - \\
\hline
\end{tabular}




\section{DISCUSSION}

These analyzes show that different elements such as the thrust of the arms in the attack jumps and of the wall, the force developed by the lower limbs, the use of an effective run-up in the jump phase and the coordination between the movements of the arms and legs, they can be decisive for assessing the potential of an athlete (Feltner et al, 1999; Harman et al, 1990). The strong correlation between VA and VW could be an indicator of an athlete's ability to transform the accumulated kinetic energy during the run-up phase into potential energy. The results of the anthropometric parameters indicate that the differentiation between roles, linked to particular morphological characteristics, that are clearly defined at senior level, are already present in the junior phase and can be used among the selection criteria in the identification of talents. Some selection indicators, such as height, $\mathrm{AH} 1$ and $\mathrm{AH} 2$ for central strikers, are linked to technical needs that depend on the evolution of the game. The central attackers must decrease the flight time to intercept the attacking actions faster and faster, with the ball hit at higher elevated; a greater extension of the arms decreases the flight time needed to intercept the ball. The correct identification of the morphological characteristics and the close connection of these with the technical role becomes at this point decisive for obtaining correct results. The anthropometric height parameters, of $\mathrm{AH} 1$ and $\mathrm{AH} 2$, are decisive and selective even for the side attackers, because they are closely related to the performance of jumping abilities in specific attack and wall gestures (VA and VW). The results of the Bosco tests showed no difference between the different roles in terms of jumping ability among young volleyball players. These results confirm the link between the morphological characteristics, the orientation towards specialization and the training of individualized muscular qualities. Finally, the analysis of the correlation matrix (Table 5) shows that most of the anthropometric variables are correlated with each other: in particular, height with weight and $\mathrm{AH} 1$ and $\mathrm{AH} 2$. In relation to the different parameters of the jump capacities, we have verified that all the anthropometric variables are positively correlated with the VA and the VW, and negatively with the SJ.

\section{CONCLUSIONS}

The anthropometric profile of volleyball players is directly linked to specific variables that must be used for the selection of young talents and for the programming of training linked to the specific role. Modern volleyball, due to the reduced duration of play and increasing intensity of rhythm, it commits much more the anaerobic alactacid metabolism; therefore, we are increasingly in need of fast and powerful athletes. The evaluation, training and continuous monitoring of the jump, in relation to the technical-tactical aspects and conditional skills, become an important aspect for the control of the performance and the possibility of identifying new talents.

\section{REFERENCES}

Altavilla, G., \& Raiola, G. (2018). Periodization: finalization of the training units and of the load's entity, The European Proceedings of Social \& Behavioural Sciences EpSBS. ICPESK 2017 International Congress of Physical Education, Sport and Kinetotherapy, eISSN: 2357-1330.

Altavilla, G., Riela, L., Di Tore, P.A., Raiola, G. (2017). The physical effort required from professional football players in different playing positions. Journal of Physical Education and Sport, Vol.17(3): 2007-2012.

Altavilla, G., Mazzeo, F., D’Elia, F., Raiola, G. (2018b). Physical commitment and specific work for each role in an elite soccer team, Journal of Physical Education and Sport, in press. 
Altavilla, G., D'Isanto, T., Di Tore, P., \& Raiola, G. (2018). Free throw and outcomes: Pilot study on intensive training versus extensive one. Journal of Human Sport and Exercise, in press. https://doi.org/10.14198/ihse.2018.133.02

Ashley, C.D., \& Weiss, L.W. (1994). Vertical jump performance and selected physiological characteristics of women. J Strength Cond Res; 8: 5-11.

Bobbert, M.F., Gerritsen, K.G., Litjens, M.C., Van Soest, A.J. (1996). Why is countermovement jump height greater than squat jump height? Med Sci Sports Exerc, 28(11): 1402-1412.42.

Bosco, C., Komi, P.V., Bosco, E., Nicol, C., Pulvirenti, G., Caruso, I. (1994). Influence of training on mechanical and biochemical profiles of athlete's muscles. Coaching and Sport Science Journal, 1;1: 8-13.

Bosco, C., Luhtanen, P., Komi, P.V. (1983). A simple method for measurement of mechanical power in jumping. Eur J Appl Physiol, 50(2):273-82. https://doi.org/10.1007/BF00422166

Cirillo, G., Nughes, E., Acanfora, A., Altavilla, G., D'Isanto, T. (2016) Physical and sport education testing by quantitative and qualitative tools in assessment in senior school: A proposal Sport Science, 9(suppl 1).

D'Isanto, T., Altavilla, G., Raiola, G. (2017). Teaching method in volleyball service: Intensive and extensive tools in cognitive and ecological approach, Journal of Physical Education and Sport, 17(suppl 4).

Feltner, M.E., Fraschetti, D.J., Crisp, R.J. (1999). Upper extremity augmentation of lower extremity kinetics during countermovement vertical jumps. J Sports Sci, 17:449-66. https://doi.org/10.1080/026404199365768

Fontani, G., Bonifazi, M., Lupo, C., Martelli, G., Maffei, D., Cameli, S., Polidori, F. (1998). Influence of a volleyball match on cortisol response in young athletes. Coaching and Sport Science journal, 3.1: 25-27.

Gaetano, R., Rago, V. (2014) Preliminary study on effects of hiit-high intensity intermittent training in youth soccer players Journal of Physical Education and Sport, 14 (2):148-150.

Gaetano, R. (2012)Didactics of volleyball into the educate program for coaches/trainers/technicians of Italian Federation of Volleyball (FIPAV)Journal of Physical Education and Sport, 12 (1).

Harman, E.A., Rosenstein, M.T., Frykman, P.N., Rosenstein. R.M. (1990). The effects of arms and countermovement on vertical jumping. Med Sci Sports Exerc, 22(6):825-33. https://doi.org/10.1249/00005768-199012000-00015

Katch, V.L., \& Weltman, A. (1979). Interrelationship between anaerobic power output, anaerobic capacity and aerobic power. Ergonomics, 22(3):325- 32. https://doi.org/10.1080/00140137908924616

Komi, P.V., \& Bosco, C. (1978). Utilization of stored elastic energy in extensor muscles by men and women, Med Sci. Sports, 10: 261-265.

Isaacs, L.D. (1998). Comparison of the vertec and Just Jump System for measuring height of vertical jump by young children. Percept Mot Skills, 86(2):659-63. https://doi.org/10.2466/pms.1998.86.2.659

Parisi, F., Raiola, G. (2014a). Video analysis in youth volleyball team, Journal of Human Sport and Exercise, 9, S584-S587. https://doi.org/10.14198//hse.2014.9.Proc1.50

Parisi, F., Raiola, G. (2014b) The serve in under 12-13 Italian volleyball team, Journal of Human Sport and Exercise, 9, S588-S591. https://doi.org/10.14198/ihse.2014.9.Proc1.51

Polgaze, T., \& Dawson, B. (1992). The physiological requirements of the positions in state league volleyball. Sports Coach, 15:32-37.

Rago, V., Pizzuto, F., Raiola, G. (2017). Relationship between intermittent endurance capacity and match performance according to the playing position in sub-19 professional male football players: Preliminary results, Journal of Physical Education and Sport, 17 (2). 
Raiola, G., Di Tore, P.A. (2017) Motor learning in sports science: Different theoretical frameworks for different teaching methods, Sport Science, 10 suppl 1.

Raiola, G. (2017) Motor learning and teaching method, Journal of Physical Education and Sport, 17(4).

Raiola, G., Altavilla, G., De Luca, C., Di Tore, P.A. (2016). Analysis on some aspects of the service in volleyball, Sport Science, 9(1):74-77.

Raiola, G. (2014) Teaching method in young female team of volleyball. Journal of Physical Education and Sport, 14 (1).

Raiola, G., Parisi, F., Giugno, Y., Di Tore, P.A. (2013) Video analysis applied to volleyball didactics to improve sport skills, Journal of Human Sport and Exercise, 8 (2 SUPPL). https://doi.org/10.4100/ihse.2012.8.Proc2.33

Raiola, G., Di Tore, A. (2012a) Non-verbal communication and volleyball: A new way to approach the phenomenon, Mediterranean Journal of Social Sciences, 3 (2). https://doi.org/10.5901/miss.2012.v3n2.347

Raiola, G., Di Tore, P.A. (2012b) Statistical study on bodily communication skills in volleyball to improve teaching methods, Journal of Human Sport and Exercise, 7 (2). https://doi.org/10.4100/jhse.2012.72.12

Raiola, G., Di Tore, P.A. (2012c) Bodily communication skills and its incidence on female volleyball championship to enhance didactics, Journal of Human Sport and Exercise, 7 (2), Raiola, G. (2012) Bodily communication in volleyball between human and experimental sciences, Mediterranean Journal of Social Sciences, 3 (1).

\section{(ब) $\odot \Theta$}

This title is licensed under a Creative Commons Attribution-NonCommercial-NoDerivs 4.0 Unported License. 